\title{
Pulmonary hypertension in diffuse parenchymal lung diseases is there any benefit of PAH-specific therapy?
}

The authors declare no financial disclosure

\begin{abstract}
Pulmonary hypertension (PH) is diagnosed in $40-50 \%$ of the patients with end-stage diffuse parenchymal lung diseases (DPLD), and it is associated with significant worsening of life expectancy. Latest ERS/ESC guidelines recommend best available treatment of DPLD, and long-term oxygen therapy in the patients with $\mathrm{PaO}_{2}$ less than $60 \mathrm{~mm} \mathrm{Hg}$. Pulmonary arterial hypertension (PAH)-targeted drugs are not recommended in PH-DPLD patients, due to the risk of increasing the ventilation-perfusion mismatch, and consequently worsening of hypoxaemia. Nevertheless, PAH-oriented treatment may be beneficial to selected groups of patients. The authors try to find the answer to several important questions: is there any benefit of PAH-specific therapy in PH-DPLD, who should be the candidate for PAH-specific therapy, what class of drugs is most promising, and what outcome measures should be employed?
\end{abstract}

Key words: pulmonary hypertension, diffuse parenchymal lung diseases, PAH-specific therapy

Adv. Respir. Med. 2017; 85: 216-223

\section{Introduction}

Pulmonary hypertension (PH) due to lung diseases is a precapillary $\mathrm{PH}$, defined as mean pulmonary artery pressure (mPAP) equal or higher than $25 \mathrm{~mm} \mathrm{Hg}$ and pulmonary artery wedge pressure (PAWP) not exceeding $15 \mathrm{~mm} \mathrm{Hg}$ assessed during right heart catheterisation (RHC) [1, 2]. In the latest ERS/ESC guidelines, severe $\mathrm{PH}$ due to lung diseases was characterised as MPAP $>35$ $\mathrm{mm} \mathrm{Hg}$ or mPAP $\geq 25 \mathrm{~mm} \mathrm{Hg}$ with cardiac index $<2.5 \mathrm{l} / \mathrm{min} / \mathrm{m}^{2}$ [1].

According to recent ERS/ESC classification (Table 1), diffuse parenchymal lung diseases (DPLD) as the cause of $\mathrm{PH}$ are included in two groups: group $3-$ where $\mathrm{PH}$ is regarded as the result of hypoxia and/or interstitial lung pathology, and group 5 - where multiple possible causes of PH may be taken into account [1].
Most cases of PH-DPLD concern patients with advanced lung disease with extensive lung fibrosis, nevertheless, in sarcoidosis $\mathrm{PH}$ may be related to other mechanisms, mostly to vasculopathy, found both in stage I-III patients and in those in stage IV $[3,4]$. The presence of $\mathrm{PH}$ in DPLD is an adverse prognostic factor. Life expectancy is even worse in those presenting with severe $\mathrm{PH}$.

Current ERS/ESC treatment guidelines recommend best available treatment of DPLD and long-term oxygen therapy in patients with hypoxaemia [1]. Pulmonary arterial hypertension $(\mathrm{PAH})$-specific drugs are not advised in this population, as there is no objective proof of their efficacy. Nevertheless, there are many publications concerning the therapeutic benefit of such treatment given as off-label therapy in individual patients.

Address for correspondence: Monika Szturmowicz, 1 Department of Lung Diseases, National Tuberculosis and Lung Diseases Research Institute, Warsaw, Płocka 26,

01-138 Warszawa, e-mail: monika.szturmowicz@gmail.com

DOI: 10.5603/ARM.2017.0036

Received: 28.04.2017

Copyright (C) 2017 PTChP

ISSN 2451-4934 
Table 1. Classification of pulmonary hypertension according to recent ERS/ESC guidelines [1]

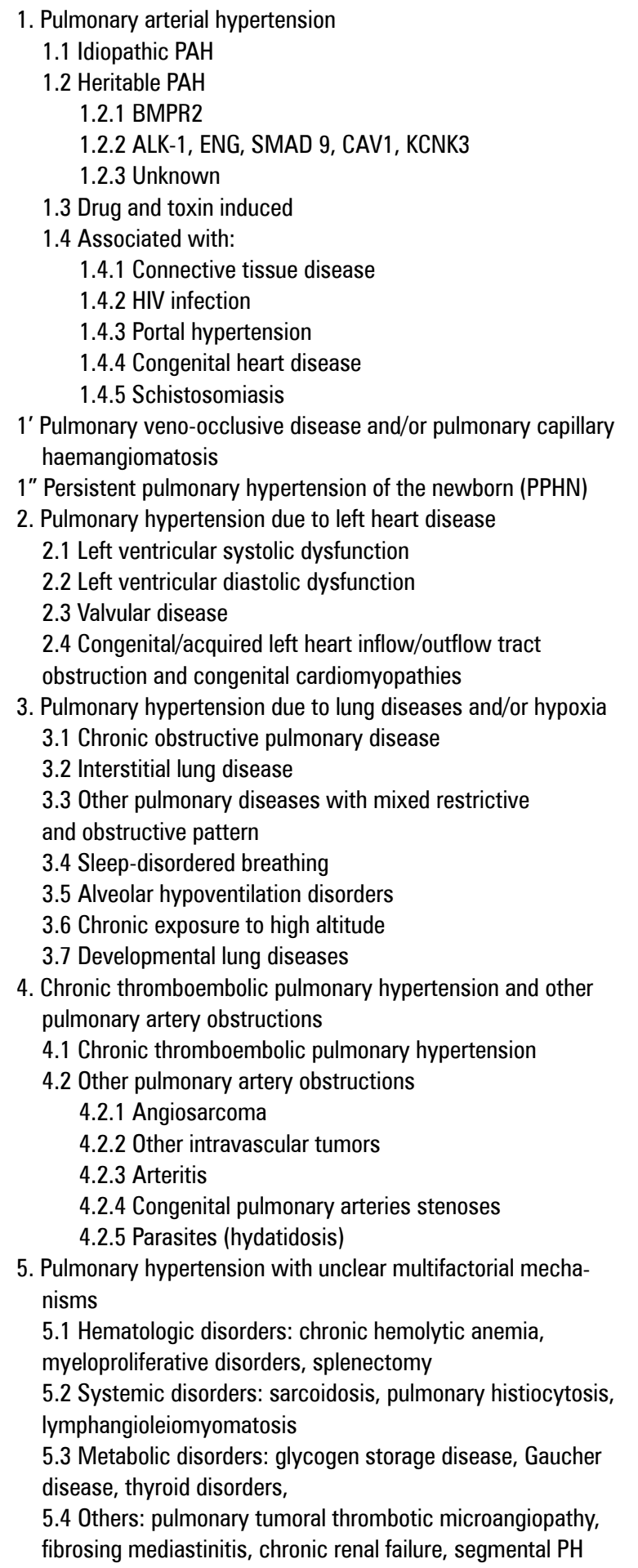

BMPR - bone morphogenic protein receptor type II; CAV1 - caveolin-1; ENG — endoglin; HIV— human immunodeficiency virus; PAH — pulmonary arterial hypertension

In the present review, we tried to summarise the up-to date information on best available treatment options possibly influencing PH-DPLD and to analyse the results of recently published clinical trials with PAH-specific drugs. DPLD belonging to group 3 such as idiopathic pulmonary fibrosis (IPF), other types of idiopathic interstitial pneumonia and hypersensitivity pneumonitis (HP), as well as those belonging to group 5 such as sarcoidosis, were included.

\section{Epidemiology of PH-DPLD}

The data on the frequency of PH in DPLD relate mostly to patients with advanced lung diseases in whom RHC was performed before lung transplantation. Three large studies performed in end-stage IPF found PH in 43-49\% of cases [5-7]. Baughman et al. [8] diagnosed precapillary $\mathrm{PH}$ in $39 \%$ of sarcoidosis patients presenting with dyspnoea despite immunosuppressive treatment, and Oliveira et al. [9] confirmed $\mathrm{PH}$ in $44 \%$ of the patients with chronic hypersensitivity pneumonitis (cHP). The prevalence of severe $\mathrm{PH}$ was estimated at $2-9 \%$ in end-stage IPF [5, 10], 10\% in cHP patients [7], and $18 \%$ in sarcoidosis refractory to immunosuppressive therapy [8]. The recent multicentre Japanese study of Tanabe et al. [11] confirmed the presence of severe $\mathrm{PH}$ in $4 \%$ of patients with IPF, $8 \%$ of patients with combined pulmonary fibrosis and emphysema (CPFE), and $10 \%$ of patients with interstitial lung diseases due to collagen tissue disease (CTD).

\section{Pathogenesis of PH-DPLD and differential diagnosis of PH causes in DPLD patients}

The presence of inflammatory or fibrotic lung disease results in alveolar hypoxia. Alveolar hypoxia generates the hypoxic vasoconstriction in the small precapillary arteries, which is an adaptive mechanism diminishing blood flow through the hypoventilated parts of the lung [12].

Chronic hypoxia causes remodelling of pulmonary arteries (PA): endothelial dysfunction, intimal fibrosis, and medial hypertrophy [12, 13]. Awano et al. [14] have recently reported on the morphology of PA remodelling in the autopsy specimens obtained from the patients with CPFE, IPF and emphysema alone. The most extensive vascular changes were described in the fibrotic areas, less extensive in the emphysematous parts of the lung. Interestingly, some arterial pathology was also found in the areas of preserved lung parenchyma, especially in the patients with CPFE [14].

PA remodelling escalates the imbalance between vascular vasodilator and vasoconstrictor factors, i.e. decrease in endogenic nitric oxide (NO) and increase in endothelin-1 [15]. 
The lung opacities seen in DPLD may result in the compression or distortion of pulmonary vessels. The phenomenon can be observed not only in the fibrotic areas but also in the hyperinflated parts of the lungs [12]. It may lead to turbulent blood flow and cause the increased shear stress that augments vasculopathy.

Pulmonary arteries may also be directly involved in the course of DPLD, especially in sarcoidosis [3, 16, 17], pulmonary Langerhans cell histiocytosis $[18,19]$, and lymphangioleiomiomatosis [12].

The differential diagnosis of other PH-related processes in DPLD patients should include postcapillary PH due to left heart insufficiency. The probability of postcapillary $\mathrm{PH}$ is highest in IPF patients because of frequent coexistence of circulatory disorders resulting from advanced age and smoking history [20]. In sarcoidosis and scleroderma, postcapillary PH may develop due to direct cardiac involvement as well $[8,21]$.

Finally, venous thromboembolic disease (VTE) should be taken into consideration as a factor contributing to severe $\mathrm{PH}$ development in patients with DPLD. According to recent publications, VTE incidence is increased both in IPF and in sarcoidosis, compared to reference healthy population [22-24]. Thus, CT-angiography should always be considered as a part of differential work-up in individuals with severe PH-DPLD.

\section{Prognosis of PH-DPLD patients}

The development of PH in DPLD patients is one of adverse prognostic factors. Baughman et al. [8] observed the worst survival in cases of $\mathrm{PH}$ due to lung disease, and much better prognosis in subjects with PH due to left heart failure, in the group of sarcoidosis patients. Takahashi et al. [25] found mPAP to be a significant independent survival predictor in DPLD associated with CTD. Data obtained from $\mathrm{PH}$ registries indicate that prognosis of the patients with severe PH-DPLD is extremely poor, with only $20-30 \%$ of patients surviving 3 years [26, 27].

\section{Current treatment options in PH-DPLD}

Recent ERS/ESC guidelines postulate the best available treatment of DPLD, and long-term oxygen therapy (LTOT) for the patients in whom resting partial oxygen pressure is lower than $60 \mathrm{~mm} \mathrm{Hg}$ [1]. Although LTOT may improve the quality of life in PH-DPLD, its influence on survival has not been proved [1].
Current treatment options for chronic fibrotic lung diseases have been summarised recently by Adegunsoye et al. [28]. The immunosuppressive therapy is often used in cHP, sarcoidosis and CTD -associated interstitial lung diseases to diminish an inflammatory component of lung infiltrates. The positive influence of such treatment on $\mathrm{PH}$ due to DPLD was reported by Sanchez et al. [29] in patients with systemic lupus erythematosus and mixed connective tissue disease, but not in systemic sclerosis (SSc).

The recent development and approval of anti-fibrotic drugs, pirfenidone and nintedanib, in IPF, was based on clinical trials showing the reduced rate of lung function decline [30-32]. The influence of pirfenidone or nintedanib on $\mathrm{PH}$ due to IPF is not easy to establish, because most trials excluded patients with end-stage lung disease, and because $\mathrm{PH}$ was not reported as a treatment related parameter [28, 33]. The mode of action of these drugs, affecting properties of fibroblasts and myofibroblasts, suggest their possible usefulness in IPF-related vasculopathy [34].

\section{Rationale for PAH-specific drugs use in PH-DPLD}

The experts' opinion concerning contradictions to the use of PAH-specific drugs in DPLD was based on the negative outcome of RCTs with endothelin receptor antagonists (ERA) - bosentan, macitentan and ambrisentan [35-38] and 5-phosphodiesterase inhibitor (5PDEi) — sildenafil [39]. Ambrisentan has been even found to increase mortality [38], and recent international guidelines stated against ambrisentan use in IPF patients [40]. Nevertheless, the results of the cited RCTs should not be extrapolated to PH-DPLD patients because the knowledge about $\mathrm{PH}$ status of the patients included in the trials was lacking.

On the other hand, there were many case reports and open label studies published, supporting thesis that $\mathrm{PAH}$-specific treatment may be beneficial to selected PH-DPLD patients [41-43].

Saggar et al. [43] reported on 15 patients with end-stage lung fibrosis and severe $\mathrm{PH}$, who experienced a substantial haemodynamic improvement being treated with intravenous treprostinil in an open prospective study.

Han et al. [44] reported significant increase in 6-minute walking distance (6MWD) in the course of sildenafil therapy compared to placebo in IPF patients presenting with right ventricular systolic dysfunction (STEP-IPF sub-study).

Zimmerman et al. [45] found significant haemodynamic improvement in 10 ILD patients 
treated with 5PDEi in the open label observational study.

The only positive randomised clinical trial (RCT) concerning PH-DPLD was published by Baughman et al. [46]. A significant decrease in mPAP was found in $23 \mathrm{PH}$-sarcoidosis patients who received 16-weeks bosentan treatment, compared to the placebo arm [46]. Other RCTs concerning $\mathrm{PAH}-$ specific treatment in patients with PH-DPLD were negative [47, 48]. Rise IIP, phase-2 study with riociguat in PH-DPLD, has been closed prematurely due to increased death rate in an active treatment arm [48].

The contradictory results of the studies cause a great need for better identification of those $\mathrm{PH}$ -DPLD patients who may benefit from vasoactive therapy. Concerns regarding the best choice of candidates for such treatment, possible differences in efficacy of various classes of $\mathrm{PAH}$-specific drugs, and optimal outcome measures, will be discussed in the following part of the text.

\section{Does the result of PAH-specific therapy in PH-DPLD patients depend on the severity of $\mathrm{PH}$ ?}

The rationale for the use of the PAH-specific drugs in PH-DPLD is based on the concept that they might slow down the development of vascular remodelling, due to their antiproliferative effect. This result may be observed after, at least, several months of treatment. Therefore, it would be important to consider PAH-specific therapy mainly in patients with longer life expectancy.

At present, however, according to recent opinion of experts published as a result of the $5^{\text {th }}$ World Symposium on Pulmonary Hypertension in Nice (Table 2), only patients with severe $\mathrm{PH}$ (mPAP > $35 \mathrm{~mm} \mathrm{Hg}$ ) in the course of DPLD should be considered as candidates for trials with PAH-specific drugs [2].
Brewis et al. [26] published recently the results of PAH-specific therapy in 118 patients with severe $\mathrm{PH}$ due to lung diseases, who were included in the Scottish PH-registry. The group included 22 patients with interstitial lung diseases; and the majority of them was treated with 5PDEi. These patients presented with well-preserved lung volumes, but very low diffusing capacity for carbon monoxide (DLCO) and severe functional and haemodynamic compromise, as well as extremely high N-terminal brain natriuretic propeptide (NT-proBNP) serum levels (Table 3). PAH-specific therapy resulted in the significant decrease in NT-proBNP, but no significant improvement in 6MWD and NYHA class were observed [26]. The prognosis was poor, 3-year survival rate was $20 \%$ [26]. Change in NT-proBNP serum levels in the course of PAH-specific therapy independently predicted survival [26].

Hoeper et al. [27] published the results of PAH-specific therapy (mostly 5PDEi) in $113 \mathrm{IPF}$ and 38 non-specific interstitial pneumonia (NSIP) patients included in the COMPERA registry. They presented with less haemodynamic compromise than the group described by Brewis et al. [26] (Table 3). As expected, their initial exercise capacity was better, and NT-pro BNP serum concentration was lower than in the Scottish group [27]. Lung volumes and DLCO were comparable to the previous study. The authors defined response to treatment as an increase in 6MWD by at least 20 meters and/ /or the functional class (FC) improvement after 13 weeks of therapy [27]. The percentage of treatment responders was comparable in the groups of patients with severe and non-severe $\mathrm{PH}$. The responders had significantly better life expectancy compared to non-responders: 3-year survival rates were $41.7 \%$ and $33.9 \%$ respectively, $p=0.048$ [27].

The results of the above mentioned studies indicate that in the patients with severe PH-ILD,

\section{Table 2. Recommendations concerning management of PH in the patients with lung diseases, according to experts on $5^{\text {th }}$ World PH Conference in Nice [2]}

\begin{tabular}{|c|c|c|c|}
\hline Clinical characteristics & mPAP $<25$ mm Hg & mPAP 25-34 mm Hg & $\mathrm{mPAP} \geq 35 \mathrm{~mm} \mathrm{Hg}$ \\
\hline $\begin{array}{l}\text { FEV }_{1} \geq 60 \% \text { pred. (COPD) } \\
\text { FVC } \geq 70 \% \text { pred. (IPF) } \\
\text { CT: absence of or modest } \\
\text { abnormalities }\end{array}$ & $\begin{array}{c}\text { No } \mathrm{PH} \\
\text { No PAH specific treat- } \\
\text { ment recommended }\end{array}$ & $\begin{array}{l}\text { PH classification uncertain } \\
\text { No data supporting treat- } \\
\text { ment with PAH specific } \\
\text { drugs }\end{array}$ & $\begin{array}{c}\text { PH classification uncertain: discrimination } \\
\text { between PAH with concomitant lung disease } \\
\text { (group 1) or PH caused by lung disease (group 3) } \\
\text { Refer to a center with expertise in both } \mathrm{PH} \text { and } \\
\text { chronic lung disease }\end{array}$ \\
\hline $\begin{array}{l}\text { FEV }_{1}<60 \% \text { pred. (COPD) } \\
\text { FVC }<70 \% \text { pred. (IPF) } \\
\text { CT: Combined pulmonary } \\
\text { fibrosis and emphysema }\end{array}$ & $\begin{array}{c}\text { No PH } \\
\text { No PAH specific treat- } \\
\text { ment recommended }\end{array}$ & $\begin{array}{l}\text { PH-COPD, PH-IPF, PH- CPFE } \\
\text { No data currently support } \\
\text { treatment with PAH-specific } \\
\text { drugs }\end{array}$ & $\begin{array}{l}\text { Severe PH-COPD, severe PH-IPF, severe PH-CPFE } \\
\text { Refer to a center with expertise in both PH and } \\
\text { chronic lung disease for individualized patient } \\
\text { care because of poor prognosis: randomized } \\
\text { controlled trials required }\end{array}$ \\
\hline
\end{tabular}


Table 3. Comparison of patients' demographics and baseline characteristics in two PH-registries reporting the efficacy of PAH-specific therapy in PH-DPLD

\begin{tabular}{|c|c|c|c|c|c|c|}
\hline Reference & $\begin{array}{c}\text { RHC } \\
\text { Mean (SD) }\end{array}$ & $\begin{array}{l}\text { No of pts/ } \\
\text { /diagnosis }\end{array}$ & $\begin{array}{c}\text { TLC } \\
\text { \%pred. } \\
\text { Mean (SD) }\end{array}$ & $\begin{array}{l}\text { DLCO \%pred. } \\
\text { Mean (SD) }\end{array}$ & $\begin{array}{l}\text { 6MWD m } \\
\text { Mean (SD) }\end{array}$ & $\begin{array}{r}\text { NT-proBNP pg/m } \\
\text { Median (range) }\end{array}$ \\
\hline $\begin{array}{l}\text { Brewis et al. ERJ } \\
2015 \text { [26] }\end{array}$ & $\begin{array}{l}\text { mPAP } 46(8) \mathrm{mm} \mathrm{Hg} \text {, } \\
\text { mRAP } 10(6) \mathrm{mm} \mathrm{Hg} \\
\mathrm{Cl} 1.9(0.5) \mathrm{l} / \mathrm{min} / \mathrm{m}^{2}\end{array}$ & 22 ILD & 74 (17) & $28(11)$ & 184 (132) & $\begin{array}{c}2474 \\
(1229-4115)\end{array}$ \\
\hline $\begin{array}{l}\text { Hoeper et al. } \\
\text { PLoS ONE } 2015 \\
\text { [27] }\end{array}$ & $\begin{array}{c}\text { mPAP } 37(9) \mathrm{mm} \mathrm{Hg}, \\
\text { mRAP } 5.9(4.8) \mathrm{mm} \mathrm{Hg} \\
\mathrm{Cl} 2.1(0.6) \mathrm{l} / \mathrm{min} / \mathrm{m}^{2}\end{array}$ & $\begin{array}{l}113 \text { IPF } \\
38 \text { NSIP }\end{array}$ & $68.8(17)$ & $28(15.8)$ & $251(116)$ & $\begin{array}{c}1029 \\
(373-2901)\end{array}$ \\
\hline
\end{tabular}

the life expectancy is very poor. Functional improvement in the course of PAH-specific therapy may be occasionally seen, and it may be combined with survival benefit. Nevertheless, it has not been proved that the patients with severe $\mathrm{PH}$ have greater probability of achieving response to therapy comparing to those with non-severe $\mathrm{PH}$.

\section{Does the result of PAH-specific therapy in PH-DPLD patients depend on the severity of lung disease?}

This problem was addressed by experts during the $5^{\text {th }}$ World Symposium on Pulmonary Hypertension in Nice, who concluded that patients characterised by mild lung parenchymal abnormalities and mild disturbances of lung volumes on PFT, but with a haemodynamic 'PAH phenotype', i.e. severe PH with high PVR and low CO, may be regarded as PAH coexisting with lung disease (Table 2). Such patients may be treated according to the recommendations for $\mathrm{PAH}$, keeping in mind the potential implications of the coexisting lung disease on symptoms and response to therapy [1].

The influence of mild to moderate lung disease on the results of PAH-specific treatment has been shown in studies including patients with PAH due to CTD, presenting with various degree of interstitial lung disease [49-51]. Condliffe et al. [49] reported worse survival of PAH-CTD patients with interstitial lung disease compared to those with no interstitial lung disease - 3-year survival rates were $28 \%$ and $47 \%$ respectively, $p$ $=0.005$. Le Pavec et al. [50] analysed the effect of PAH-specific drugs in 70 scleroderma patients with PAH (mean mPAP $-43 \mathrm{~mm} \mathrm{Hg}$ ) and interstitial lung disease. The patients presented with restrictive ventilation pattern (mean TLC - 61\% of predicted) and low DLCO - 34\% of predicted. The majority of them received ERAs. No significant changes were observed in WHO functional class, 6MWD or haemodynamic parameters after
7 months of therapy [50]. The prognosis was poor despite treatment, only $21 \%$ of patients survived 3 years [50]. On the other hand, scleroderma patients with comparable haemodynamic characteristics and mode of therapy, but without interstitial lung disease, had much better life expectancy ( $56 \%$ survived 3 years) in the report of Launay et al. [51].

Thus, it seems that patients with PAH phenotype and more than mild lung disease have lower probability of successful PAH-specific therapy.

\section{Is the treatment efficacy related to the class of PAH-specific drugs?}

One of the most important potential adverse effects of PAH-specific treatment is the decrease of oxygenation due to increased ventilation-perfusion mismatch. This effect may be partly dependent on the type of PAH-specific drug. Ghofrani et al. [52] demonstrated an increase in ventilation -perfusion mismatch and a decrease in oxygen saturation only in those IPF patients who received a single dose of intravenous epoprostenol, but not in those who were administered inhaled nitric oxide or a single oral dose of sildenafil. Milara et al. [53] have recently published the study on vascular effects of sildenafil in explanted lungs. They showed that sildenafil caused a vasorelaxant effect mainly in pulmonary arteries (PA) obtained from the patients with IPF without $\mathrm{PH}$ and from healthy donors. The effect was much smaller in PA obtained from the IPF with PH and from PAH lung specimens [53]. Probably, sildenafil is less active at sites with advanced PA remodelling because of markedly decreased endogenous NO, which is mandatory for sildenafil action.

The clinical studies performed both in DPLD and in PH-DPLD confirmed that sildenafil did not carry a significant risk of worsening of oxygenation $[26,27,39,45]$. 
On the other hand, open label study with riociguat, a soluble guanylate cyclase stimulator, that acts independently of endogenous NO, demonstrated decreased oxygenation in $\mathrm{PH}$ due to various DPLD [54].

The data concerning ERA compound - bosentan are more contradictory. Baughman et al. [46] reported increase of oxygen demands by $>2 \mathrm{l} / \mathrm{min}$ in 2 out of 23 sarcoidosis patients in the bosentan arm. Nevertheless, the increase of desaturation rate observed during $6 \mathrm{MWT}$ by week 16 was similar in the bosentan and placebo arms $-21 \%$ and $22 \%$ respectively [46].

Corte et al. [47] did not find a significant difference in desaturation rate in IPF and NSIP patients treated with bosentan compared to the placebo arm.

\section{What should be the optimal outcome measure in a trial regarding PAH-specific treatment in PH-DPLD?}

There is no consensus in terms of the best endpoints in clinical studies on pulmonary vasoactive agents in PH-DPLD. One of the early indicators of treatment efficacy is a decrease in NT -proBNP serum concentration. Bonham et al. [55] found that NT-proBNP levels normalised in all patients with $\mathrm{PH}$ and sarcoidosis who survived 3 years on treatment with prostacyclin and oral vasodilator therapy. Median NT-proBNP concentration in 11 patients before treatment was 2207 $\mathrm{pg} / \mathrm{ml}$, and $49 \mathrm{pg} / \mathrm{ml}$ in 6 of them who survived 3 years. The decrease of serum NT-proBNP in the course of PAH-targeted therapy was also noted by Brewis et al. [26]; however, the post-treatment values were still markedly elevated.

Haemodynamic variables were used as primary endpoints in many open label studies [43, 45, 54] and some of RCTs [46, 47]. Positive influence of PAH-directed therapy on haemodynamic variables was found in most open label studies, but this effect was not always seen in RCTs. Baughman et al. [46] found significant decrease of mPAP and PVR in sarcoidosis patients treated with bosentan, but Corte et al. [47] did not observe any influence of bosentan on haemodynamic variables in PH due to IPF and NSIP.

The improvement of functional status in $\mathrm{PH}$ -DPLD seems to be most important as an outcome measure. Positive influence of PAH-specific treatment on functional class (FC) was reported by Corte et al. and Hoeper et al. [27, 47], and increase in $6 \mathrm{MWD}$ by $20 \mathrm{~m}$ by Hoeper et al. [27], but it was not observed in the Baughman et al. [46] study. The data from the COMPERA registry indicated the possibility of survival benefit in responders to PAH-specific therapy, nevertheless, the survival benefit was not large [27].

Finally, the measures concerning the quality of life are gaining much attention recently. This issue has been addressed in STEP-IPF RCT, which showed significant improvement in dyspnoea index, and quality of life measured by St. George's Respiratory Questionnaire (SGRQ) in IPF patients treated with sildenafil, compared to the placebo arm [39]. The sub-analysis of STEP-IPF, concerning patients with known right ventricular dysfunction confirmed greater improvement in SGRQ and EuroQol visual analogue scores in subjects treated with sildenafil compared to those in the placebo arm [44]. Nevertheless, Corte et al. [47] have not found the improvement in life quality measured by the CAMPHOR questionnaire in the patients with IPF and NSIP treated with bosentan compared to placebo [47].

\section{Summary}

Based on the current status of knowledge, PAH-targeted therapy is not recommended in PH-DPLD patients. Such treatment may be considered, only in experienced centres, in the following patients:

1) with severe PH and mild DPLD, as such phenotype might be suggestive of $\mathrm{PAH}$ coexisting with lung disease;

2) with severe PH and severe DPLD, participating in clinical trials addressing possible treatment effectiveness.

5PDEis seem to have better profile in PH-DPLD patients, e.g. smaller effect on ventilation-perfusion mismatch compared to other classes of PAH-specific drugs.

Patients with severe $\mathrm{PH}$ and severe lung disease are less likely to improve functional status, and consequently have less chance of survival improvement compared to those with severe $\mathrm{PH}$ and mild lung disease. Thus, further studies within PH-DPLD patients population are needed to answer pivotal questions on who, how and with what expectations could be treated with PAH-specific therapy.

\section{References:}

1. Galiè N, Humbert M, Vachiery JL, et al. 2015 ESC/ERS Guidelines for the diagnosis and treatment of pulmonary hypertension: The Joint Task Force for the Diagnosis and Treatment of Pulmonary Hypertension of the European Society of Cardiology (ESC) and the European Respiratory Society (ERS): Endorsed by: Association for European Paediatric and Congenital Cardiology (AEPC), International Society for Heart 
and Lung Transplantation (ISHLT). Eur Respir J. 2015; 46(4): 903-975, doi: 10.1183/13993003.01032-2015, indexed in Pubmed: 26318161.

2. Seeger W, Adir Y, Barberà JA, et al. Pulmonary hypertension in chronic lung diseases. J Am Coll Cardiol. 2013; 62(25 Suppl): D109-D116, doi: 10.1016/j.jacc.2013.10.036, indexed in Pubmed: 24355635.

3. Nunes H, Humbert M, Capron F, et al. Pulmonary hypertension associated with sarcoidosis: mechanisms, haemodynamics and prognosis. Thorax. 2006; 61(1): 68-74, doi: 10.1136/ thx.2005.042838, indexed in Pubmed: 16227329.

4. Shorr AF, Helman DL, Davies DB, et al. Pulmonary hypertension in advanced sarcoidosis: epidemiology and clinical characteristics. Eur Respir J. 2005; 25(5): 783-788, doi: 10.1183/09031936.05.00083404, indexed in Pubmed: 15863633.

5. Shorr AF, Wainright JL, Cors CS, et al. Pulmonary hypertension in patients with pulmonary fibrosis awaiting lung transplant. Eur Respir J. 2007; 30(4): 715-721, doi: 10.1183/09031936.00107206, indexed in Pubmed: 17626111.

6. Modrykamien AM, Gudavalli R, McCarthy K, et al. Echocardiography, 6-minute walk distance, and distance-saturation product as predictors of pulmonary arterial hypertension in idiopathic pulmonary fibrosis. Respir Care. 2010; 55(5): 584588, indexed in Pubmed: 20420729.

7. Hayes D, Higgins RS, Black SM, et al. Effect of pulmonary hypertension on survival in patients with idiopathic pulmonary fibrosis after lung transplantation: an analysis of the United Network of Organ Sharing registry. J Heart Lung Transplant. 2015; 34(3): 430-437, doi: 10.1016/j.healun.2014.09.004, indexed in Pubmed: 25444371.

8. Baughman RP, Engel PJ, Taylor L, et al. Survival in sarcoidosis-associated pulmonary hypertension: the importance of hemodynamic evaluation. Chest. 2010; 138(5): 1078-1085, doi: 10.1378/chest.09-2002, indexed in Pubmed: 20348196.

9. Oliveira RKF, Pereira CAC, Ramos RP, et al. A haemodynamic study of pulmonary hypertension in chronic hypersensitivity pneumonitis. Eur Respir J. 2014; 44(2): 415-424, doi: 10.1183/09031936.00010414, indexed in Pubmed: 24743965.

10. Lettieri CJ, Nathan SD, Barnett SD, et al. Prevalence and outcomes of pulmonary arterial hypertension in advanced idiopathic pulmonary fibrosis. Chest. 2006; 129(3): 746-752, doi: 10.1378/chest.129.3.746, indexed in Pubmed: 16537877.

11. Tanabe N, Taniguchi H, Tsujino I. Multi-institutional retrospective cohort study of patients with severe pulmonary hypertension associated with respiratory disease. Respirology. 2015; 20(5): 605-812.

12. Shlobin OA, Brown AW, Nathan SD. Pulmonary Hypertension in Diffuse Parenchymal Lung Diseases. Chest. 2017; 151(1): 204-214, doi: 10.1016/j.chest.2016.08.002, indexed in Pubmed: 27554299.

13. Dunham-Snary KJ, Wu D, Sykes EA, et al. Hypoxic Pulmonary Vasoconstriction: From Molecular Mechanisms to Medicine. Chest. 2017; 151(1): 181-192, doi: 10.1016/j.chest.2016.09.001, indexed in Pubmed: 27645688.

14. Awano N, Inomata M, Ikushima S, et al. Histological analysis of vasculopathy associated with pulmonary hypertension in combined pulmonary fibrosis and emphysema: comparison with idiopathic pulmonary fibrosis or emphysema alone. Histopathology. 2017; 70(6): 896-905, doi: 10.1111/his.13153, indexed in Pubmed: 27992963.

15. Ventetuolo CE, Kawut SM, Lederer DJ. Plasma endothelin-1 and vascular endothelial growth factor levels and their relationship to hemodynamics in idiopathic pulmonary fibrosis. Respiration. 2012; 84(4): 299-305, doi: 10.1159/000339105, indexed in Pubmed: 22869459.

16. Polomis D, Runo JR, Meyer KC. Pulmonary hypertension in interstitial lung disease. Curr Opin Pulm Med. 2008; 14(5): 462-469, doi: 10.1097/MCP.0b013e3283043e30, indexed in Pubmed: 18664977.

17. Nathan SD. Pulmonary hypertension in interstitial lung disease. Int J Clin Pract Suppl. 2008(160): 21-28, indexed in Pubmed: 18720579.

18. Fartoukh M, Humbert M, Capron F, et al. Severe pulmonary hypertension in histiocytosis X. Am J Respir Crit Care Med. 2000;
161(1): 216-223, doi: 10.1164/ajrccm.161.1.9807024, indexed in Pubmed: 10619823.

19. Dauriat G, Mal H, Thabut G, et al. Lung transplantation for pulmonary langerhans' cell histiocytosis: a multicenter analysis. Transplantation. 2006; 81(5): 746-750, doi: 10.1097/01. tp.0000200304.64613.af, indexed in Pubmed: 16534477.

20. Fulton BG, Ryerson CJ. Managing comorbidities in idiopathic pulmonary fibrosis. Int J Gen Med. 2015; 8: 309-318, doi: 10.2147/IJGM.S74880, indexed in Pubmed: 26451121.

21. Le Pavec J, Humbert M, Mouthon L, et al. Systemic sclerosis -associated pulmonary arterial hypertension. Am J Respir Crit Care Med. 2010; 18(12): 1285-1293.

22. Dalleywater W, Powell HA, Fogarty AW, et al. Venous thromboembolism in people with idiopathic pulmonary fibrosis: a population-based study. Eur Respir J. 2014; 44(6): 17141715, doi: 10.1183/09031936.00099614, indexed in Pubmed: 25323238.

23. Swigris JJ, Olson AL, Huie TJ, et al. Increased risk of pulmonary embolism among US decedents with sarcoidosis from 1988 to 2007. Chest. 2011 ; 140(5): 1261-1266, doi: 10.1378/ chest.11-0324, indexed in Pubmed: 21565969.

24. Vorselaars ADM, Snijder RJ, Grutters JC. Increased number of pulmonary embolisms in sarcoidosis patients. Chest. 2012; 141(3): 826-827, doi: 10.1378/chest.11-2514, indexed in Pubmed: 22396572 .

25. Takahashi K, Taniguchi H, Ando M, et al. Mean pulmonary arterial pressure as a prognostic indicator in connective tissue disease associated with interstitial lung disease: a retrospective cohort study. BMC Pulm Med. 2016; 16(1): 55, doi: 10.1186/ s12890-016-0207-3, indexed in Pubmed: 27094018.

26. Brewis MJ, Church AC, Johnson MK, et al. Severe pulmonary hypertension in lung disease: phenotypes and response to treatment. Eur Respir J. 2015; 46(5): 1378-1389, doi: 10.1183/13993003.02307-2014, indexed in Pubmed: 26293503.

27. Hoeper MM, Behr J, Held M, et al. Pulmonary Hypertension in Patients with Chronic Fibrosing Idiopathic Interstitial Pneumonias. PLoS One. 2015; 10(12): e0141911, doi: 10.1371/journal pone.0141911, indexed in Pubmed: 26630396.

28. Adegunsoye A, Strek ME. Therapeutic Approach to Adult Fibrotic Lung Diseases. Chest. 2016; 150(6): 1371-1386, doi: 10.1016/j.chest.2016.07.027, indexed in Pubmed: 27521738.

29. Sanchez O, Sitbon O, Jaïs X, et al. Immunosuppressive therapy in connective tissue diseases-associated pulmonary arterial hypertension. Chest. 2006; 130(1): 182-189, doi: 10.1378/ chest.130.1.182, indexed in Pubmed: 16840400.

30. King TE, Bradford WZ, Castro-Bernardini S, et al. ASCEND Study Group. A phase 3 trial of pirfenidone in patients with idiopathic pulmonary fibrosis. N Engl J Med. 2014; 370(22): 2083-2092, doi: 10.1056/NEJMoa1402582, indexed in Pubmed: 24836312.

31. Richeldi LR, du Bois RM, Raghu G. Efficacy and safety of nintedanib in idiopathic pulmonary fibrosis. N Engl J Med. 2014; 370(22): 2071-2082.

32. Noble PW, Albera C, Bradford WZ, et al. Pirfenidone for idiopathic pulmonary fibrosis: analysis of pooled data from three multinational phase 3 trials. Eur Respir J. 2016; 47(1): 243253, doi: 10.1183/13993003.00026-2015, indexed in Pubmed: 26647432 .

33. Nathan SD, Behr J, Cottin V, et al. Idiopathic interstitial pneumonia-associated pulmonary hypertension: A target for therapy? Respir Med. 2017; 122 Suppl 1: S10-S13, doi: 10.1016/j.rmed.2016.11.003, indexed in Pubmed: 27884593.

34. Lehtonen ST, Veijola A, Karvonen H, et al. Pirfenidone and nintedanib modulate properties of fibroblasts and myofibroblasts in idiopathic pulmonary fibrosis. Respir Res. 2016; 17: 14, doi: 10.1186/s12931-016-0328-5, indexed in Pubmed: 26846335.

35. King TE, Behr J, Brown KK, et al. BUILD-1: a randomized placebo-controlled trial of bosentan in idiopathic pulmonary fibrosis. Am J Respir Crit Care Med. 2008; 177(1): 75-81, doi: 10.1164/rccm.200705-732OC, indexed in Pubmed: 17901413.

36. King TE, Brown KK, Raghu G, et al. BUILD-3: a randomized, controlled trial of bosentan in idiopathic pulmonary fibrosis. Am J Respir Crit Care Med. 2011; 184(1): 92-99, doi: 10.1164/ rccm.201011-18740C, indexed in Pubmed: 21474646.

37. Raghu G, Million-Rousseau R, Morganti A, et al. MUSIC Study Group. Macitentan for the treatment of idiopathic pulmonary 
fibrosis: the randomised controlled MUSIC trial. Eur Respir J. 2013; 42(6): 1622-1632, doi: 10.1183/09031936.00104612, indexed in Pubmed: 23682110.

38. Raghu G, Behr J, Brown KK, et al. ARTEMIS-IPF Investigators*. Treatment of idiopathic pulmonary fibrosis with ambrisentan: a parallel, randomized trial. Ann Intern Med. 2013; 158(9): 641-649, doi: 10.7326/0003-4819-158-9-201305070-00003, indexed in Pubmed: 23648946.

39. Zisman DA, Schwarz M, Anstrom KJ, et al. Idiopathic Pulmonary Fibrosis Clinical Research Network. A controlled trial of sildenafil in advanced idiopathic pulmonary fibrosis. N Engl J Med. 2010; 363(7): 620-628, doi: 10.1056/NEJMoa1002110, indexed in Pubmed: 20484178.

40. Rhagu G, Rochwerg B, Zhang Y, et al. An Official ATS/ERS/ JRS/ALAT Clinical Practice Guideline: treatment of idiopathic pulmonary fibrosis an update of the 2011 clinical practice guideline. Am J Respir Crit Care Med. 2015; 192(2): e3-e19.

41. May A, Kane G, Yi E, et al. Dramatic and sustained responsiveness of pulmonary Langerhans cell histiocytosis-associated pulmonary hypertension to vasodilator therapy. Respir Med Case Rep. 2015; 14: 13-15, doi: 10.1016/j.rmcr.2014.11.005, indexed in Pubmed: 26029568.

42. Keir GJ, Walsh SLF, Gatzoulis MA, et al. Treatment of sarcoidosis-associated pulmonary hypertension: A single centre retrospective experience using targeted therapies. Sarcoidosis Vasc Diffuse Lung Dis. 2014; 31(2): 82-90, indexed in Pubmed: 25078636.

43. Saggar R, Khanna D, Vaidya A, et al. Changes in right heart haemodynamics and echocardiographic function in an advanced phenotype of pulmonary hypertension and right heart dysfunction associated with pulmonary fibrosis. Thorax. 2014; 69(2): 123-129, doi: 10.1136/thoraxinl-2013-204150, indexed in Pubmed: 24431095.

44. Han MK, Bach DS, Hagan PG, et al. IPFnet Investigators. Sildenafil preserves exercise capacity in patients with idiopathic pulmonary fibrosis and right-sided ventricular dysfunction. Chest. 2013; 143(6): 1699-1708, doi: 10.1378/chest.12-1594, indexed in Pubmed: 23732584.

45. Zimmermann GS, von Wulffen W, Huppmann P, et al. Haemodynamic changes in pulmonary hypertension in patients with interstitial lung disease treated with PDE-5 inhibitors. Respirology. 2014; 19(5): 700-706, doi: 10.1111/resp.12294, indexed in Pubmed: 24697923.
46. Baughman RP, Culver DA, Cordova FC, et al. Bosentan for sarcoidosis-associated pulmonary hypertension: a double-blind placebo controlled randomized trial. Chest. 2014; 145(4): 810-817, doi: 10.1378/chest.13-1766, indexed in Pubmed: 24177203.

47. Corte TJ, Keir GJ, Dimopoulos K, et al. BPHIT Study Group. Bosentan in pulmonary hypertension associated with fibrotic idiopathic interstitial pneumonia. Am J Respir Crit Care Med. 2014; 190(2): 208-217, doi: 10.1164/rccm.201403-0446OC, indexed in Pubmed: 24937643.

48. https://clinicaltrials.gov/ct2/show/NCT02138825.

49. Condliffe R, Kiely DG, Peacock AJ, et al. Connective tissue disease-associated pulmonary arterial hypertension in the modern treatment era. Am J Respir Crit Care Med. 2009; 179(2): 151-157, doi: 10.1164/rccm.200806-953OC, indexed in Pubmed: 18931333.

50. Le Pavec J, Girgis RE, Lechtzin N. Systemic sclerosis-related pulmonary hypertension associated with interstitial lung disease. Arthrit Rheum. 2011; 63(8): 2456-2464.

51. Launay D, Sitbon O, Hachulla E, et al. Survival in systemic sclerosis-associated pulmonary arterial hypertension in the modern management era. Ann Rheum Dis. 2013; 72(12): 1940-1946, doi: 10.1136/annrheumdis-2012-202489, indexed in Pubmed: 23178295.

52. Ghofrani HA, Wiedemann R, Rose F, et al. Sildenafil for treatment of lung fibrosis and pulmonary hypertension: a randomised controlled trial. Lancet. 2002; 360(9337): 895-900, doi: 10.1016/S0140-6736(02)11024-5, indexed in Pubmed: 12354470.

53. Milara J, Escrivá J, Ortiz JL, et al. Vascular effects of sildenafil in patients with pulmonary fibrosis and pulmonary hypertension: an ex vivo/in vitro study. Eur Respir J. 2016; 47(6): 1737-1749, doi: 10.1183/13993003.01259-2015, indexed in Pubmed: 27009174.

54. Hoeper MM, Halank M, Wilkens $\mathrm{H}$, et al. Riociguat for interstitial lung disease and pulmonary hypertension: a pilot trial. Eur Respir J. 2013; 41(4): 853-860, doi: 10.1183/09031936.00213911, indexed in Pubmed: 22936711.

55. Bonham CA, Oldham JM, Gomberg-Maitland M, et al. Prostacyclin and oral vasodilator therapy in sarcoidosis-associated pulmonary hypertension: a retrospective case series. Chest. 2015; 148(4): 1055-1062, doi: 10.1378/chest.14-2546, indexed in Pubmed: 26437815. 